\title{
The Impact of Chronic Diseases on Patients and Their Families: Case of Ulceratice Colitis and Crohn's Disease
}

\author{
Maria Tsoukka ${ }^{1,2 *}$, Eleni Jelastopulu ${ }^{1,3}$, Panagiota Evangelou ${ }^{4}$ and George Charalambous ${ }^{1,5}$ \\ ${ }^{1}$ Frederick University, Cyprus \\ ${ }^{2}$ General Hospital of Larnaca, Cyprus \\ ${ }^{3}$ Department of Public Health, School of Medicine, University of Patras, Greece \\ ${ }^{4}$ Undergraduate Medical School, University of Cyprus, Cyprus \\ ${ }^{5}$ General Hospital of Athens Hippocratio, Greece \\ *Corresponding author: Maria Tsoukka, Frederick University, General Hospital of Larnaca, Kalavardon No. 16, Dromolaxia, 7020 Larnaca, Cyprus
}

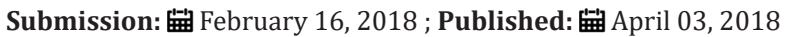

\begin{abstract}
Background: The purpose of the study is to identify the potential psychological effects of ulcerative colitis and Crohn's disease on patients and their family environment.

Aim: The objective aims of this current research are to identify the causal factors creating psychological problems among patients and their family members, exploring ways to eliminate them and create a general picture for their psychological condition in relation to the diseases at a Pancyprian level.

Methods: The Greek translation of the Hospital Anxiety and Depression Scale (HADS) and the Greek translation of the Health Survey (SF-12) will be used for evaluating the psychological effects of ulcerative colitis and Crohn disease on patients and their families. In addition, the Greek translation of the inflammatory Bowel Disease Questionnaire will be used only on the patients. The questionnaires will be handed out to the patients and their attendants in Gastroenterology dispensaries all over Cyprus.

Conclusion: In the context of improving health care quality, it was indicated that multifaceted interventions are more effective than simpler interventions and that the insistence on change requires a multi-layered approach. A major focus of health policy is the effective management of long term diseases both for reducing the burden on patients and professionals as well as of the health services also. Studying the Group of patients with IBD could be an important example of study as the patients themselves are chronic patients with 20 years being the peak age onset of the diseases and life expectancy of healthy individuals.
\end{abstract}

Keywords: Crohn's disease; Health related quality of life; Short inflammatory bowel disease; questionnaire; Ulcerative colitis; SF-12, HADS; Anxiety

\section{Introduction}

The idiopathic Inflammatory Bowel Diseases (IBD) are nosological entities which are characterized by chronic relapsing immune activation and inflammation of the gastrointestinal tract. The main forms of these chronic diseases are ulcerative colitis (UC) and Crohn's disease (CD). Crohn's disease can infect any part of the digestive tract whereas ulcerative colitis can affect only the colon. They take place with remissions and relapses and have a direct impact on patient's way of life [1].

Although the role of stress in relation to IBD has not been established, however there is no doubt that stress is a factor of activation and worsening compared to the course of action and symptoms of IBD $[2,3]$. Also, it is noted that they suffer most often from psychological disorders compared to healthy individuals. In general, the prevalence of anxiety and depression is significantly higher in individuals who suffer from gastroenterological diseases than in the general population [4,5]. In particular, regarding inflammatory diseases the rate of anxiety and depression have been estimated at $29-35 \%$ during the remission period [6,7] and during the relapsing period at $80 \%$ for anxiety and $60 \%$ for depression [8].

Chronic illness to any member of a family is known to affect the quality of life of all of its family members. According to a recent research it has been reported that the family members of these patients, were influenced to a very large percentage in the emotional field, daily activities and in their family relations $[9,10]$. 


\section{Materials and Methods}

The method of the research is quantitative using structured questionnaires, which were given out anonymously to maintain the security of personal data. The results of this research will be targeted to all health parties involved, both in level of patients as well as in level of education and improvement in quality health services. Both patients and the whole healthcare system will be benefited as a health system based on primary health care is going to be implemented. Through this research, the qualitative approach of patients with IBD and also the provision of high quality services are focusing on the patient, the needs and expectations of the outcome and the correct use of health services, increase performance, productivity and containment of costs are promoted.

Research will be processed using structured questionnaires which were provided in printed form in patients with IBD monitored in Gastroenterology dispensaries and also given out to relatives accompanying them, in all general hospitals in Cyprus, as well as to the largest private clinics after being authorized by the owners.

In terms of research design, the research is a non-experimental cross-sectional study. Independent variables being the kind of the disease (Crohn, ulcerative colitis), age, gender and others. Dependent variable of the study is the psychological status of both patients and relatives, in relation to the diseases and the intensity of the symptoms of sufferers. Survey data started being collected immediately after the granting of the relevant license authorization by the Ministry of Health, the Committee of Bioethics and Personal Data.

The Greek translation of The Hospital Anxiety and Depression Scale (HADS) [11], will be used for evaluating the psychological effects of ulcerative colitis and Crohn's disease in both, the patients and their relatives after granting the necessary permissions. HADS is a special tool for measuring mood disorder, psychosomatic effects and in particular of anxiety and depression in non-psychiatric patients [12]. It consists of fourteen questions seven questions of which reflect anxiety and the other seven questions reflect depression. These questions are answered by the patient in four points $(0-3)$ so that the possible scores will range from $0-21$ for anxiety and 0-21 for depression. For the responses of two subscales with score 0-7, the tool indicates normal mood, for 8-10 it indicates mild disorder and from 11 and upwards it indicates moderate and severe disorder respectively [12].

Also, the Greek translation of the SF-12, which is provided by the quality metric health outcomes, will be used. The questionnaire SF-12 calculates the four dimensions of the SF 36 with two elements (physical functionality, physical role, emotional role and mental health) and the remaining four with one element (body pain, General health, vitality and social functionality). These twelve elements are used in the calculation of the physical and psychological health component, through an algorithm that turned out empirically from the general U.S.A. population data and which was sent analytically for use during the purchase of the questionnaire. http://www. qualitymetric.com/WhatWeDo/TranslationProcess/tabid/213/ Default.aspx [13]

Additionally, the Greek translation of the inflammatory bowel disease questionnaire (IBDQ) will be used only in patients with IBD; it is a special tool used for measuring the quality of life of the population in patients with IBD [14]. The IBDQ is characterized by significant ability to detect differentiations in the quality of life of patients with IBD when changes are observed in the clinical development and evolution of the disease [15]

The IBDQ includes 32 questions. Each question can be answered with 7 possible answers which banded from the 1st 7 th, give rating 1-7. No 1 corresponds to a response that indicates a serious problem and 7 given in answers indicating the absence of a problem. Responses with scores in between indicate interim gravity of the problem and give intermediate score. The total score of the questionnaire, results from the sum of the scores that correspond to the answers. The higher the total score, the better the quality of life of the patient who filled out the questionnaire. The scale was given by the Mc Master University where I purchased the questionnaire from.

\section{Research Questions and Hypothesis}

In recent years scientific opinion has been concerned strongly by the relationship between the psychological factors and diseases, Ulcerative Colitis, Crohn's disease. Thus, with this research we seek to answer some of the questions that might be associated with patients suffering from IBD in Cyprus. Can the course of these chronic diseases in combination with the uncertainty and predictability that they develop, can cause psychological and interpersonal concerns to patients with IBD? As a lot of concerns arise during the period of the disease special handling and appropriate treatment is needed to calm down the concerns of the patients and their family members helping them to adjust into the situation of the disease.

Are the General characteristics of the patients and their family members maybe related with the development of psychological concerns, in relation to their diseases? Can chronic illness in a family member affect the quality of life and the emotional level of those involved in patient care? Can the therapy be associated with the psychological reactions of those patients? Is the psychological mood of patients and people accompanying them, affected adversely during the relapsing period of these diseases? These and much more other questions can arise and be answered by this research in Cyprus. In terms of research we can assume that the unpredictable, uncertainty and chronic disease course in patients with IBD, can cause a wide range of psychological and interpersonal disturbances. Even the loss of bowel control can lead to the reduction of self-respect and develop a sense of stigma. Also, we can assume that a chronic illness can affect the quality of life of all family members of the patient. 


\section{Procedure of Statistics Analysis of Results}

The statistical software program IBM SPSS Statistics v.20 was used for all statistical analysis with a level of statistical significance $\mathrm{p} \leq 0.05$.

\section{Discussion}

Over time several researchers have dealt with the psychological factors, such as depression and anxiety stemming from health in chronic patients and the possibility for the disease to be a result of these factors or to have negative effects on the course of a disease. Fewer, however, dealt with the assessment of the need of these patients for support from their family or even the consequences of a chronic disease among them and their family environment [10].

It has been noted in the international literature that although the role of stress in relation to IBD has not been established, however there is no doubt that stress is a trigger factor and deterioration compared with the symptoms and the course of IBD $[16,17,18]$.

However, some researchers have referred to the belief that depression and anxiety are considered to be a consequence of the chronicity of the symptoms of the illness, conviction which is enhanced by Moser 2009, Machado de Souza et al 2011 as they have reported that one psychological change seems to be a consequence of the disease and the level of the psychological distress and disorders are associated with the severity of the disease as they determine the quality of life that affects the course of the disease [19]. In some studies it has been reported that the anxiety disorders and depression worsen during the relapsing period of the disease and in cases of moderate and severe disease with significant improvement after receiving treatment and reduction of the disease activity [20]. Also some others link psychological disorders as a result of the side effects of the medication $[19,21,22]$.

Social support has been shown to improve patients' ability to cope with the active disease and stress, as it has also been reported that the support of those patients by their family is very useful for managing IBD $[10,16,23,24,16,25,26]$.

\section{Conclusion}

From what has been spotted over time in literature, Crohn's disease and Ulcerative Colitis in combination with various intrinsic and extrinsic factors such as personality, medication, family and social environment, the self-care ability and the stage of the disease are likely to adversely affect the psychosocial and emotional level, and also reduce the quality of life for both patients and their families.

With the present research there is an attempt to create an overall picture of the potential psychological impact of the diseases on Cypriot patients and the people who are involved in their care. The main objective is the introduction of appropriate interventions to eliminate the psychological problem as a consequence of the disease and as a result to improve the quality of life for them and their families.

\section{References}

1. Baumgart DC, Carding SR (2007) Inflammatory bowel disease: Cause and immunobiology. Lancet 369(9573): 1627-1640.

2. Drossman DA, Ringel Y (2004) Psychological factors in ulcerative colitis and Crohn's disease. In: Sartor R, Sandborn W, (Eds.), Kirsner's Inflammatory Bowel Disease. WB Saunders, Philadelphia, USA, ( $6^{\text {th }}$ edn, $)$ pp. 340-356.

3. Maunder R, Levenstein S (2008) The role of stress in the development and clinical course of inflammatory bowel disease: epidemiological evidence. Curr Mol Med 8(4): 247-252.

4. Derogatis LR, Wise TN (1989) Anxiety and Depressive Disorders in the Medical Patient. American Psychiatric Press, Washington, USA.

5. Harter MC, Conway KP, Merikangas KR (2003) Associations between anxiety disorders and physical illness. Eur Arch Psychiatry Clin Neurosci 253(6): 313-320.

6. Mittermaier C, Dejaco C, Waldhoer T, Oefferlbauer-Ernst A, Miehsler $W$, et al. (2004) Impact of depressive mood on relapse in patients with inflammatory bowel disease: a prospective18-month follow-up study. Psychosom Med 66(1): 79-84.

7. Andrews H, Barczak P, Allan RN (1987) Psychiatric illness in patients with inflammatory bowel disease. Gut 28(12): 1600-1604.

8. Addolorato G, Capristo E, Stefanini GF, Gasparrini G (1997) Inflammatory bowel disease: a study of the association between anxiety and depression, physical morbidity, and nutritional status. Scand J Gastroenterol 32(10): 1013-1021.

9. Golics CJ, Basra MK, Salek MS, Finlay AY (2013) The impact of patients' chronic disease on family quality of life: an experience from 26 specialties. Int J Gen Med 6: 787-798.

10. Lahat A, Newman S, Eliakim R, Ben-Horin S (2014) Partnerd of patients' with Inflammatory Bowel Disease: how important is their support? Clin Exp Gastroenterol 7: 225-259.

11.Zigmont AS, Snaith RP (1983) The Hospital and Anxiety Depression Scale. Act a Psychiatr Scand 67(6): 361-370.

12. Snaith RP (2003) The Hospital Anxiety and Depression Scale. Health and Quality of Life Outcomes 1:29.

13. http://www.qualitymetric.com/WhatWeDo/TranslationProcess / tabid/213/Default.aspx

14. Pallis AG, Vlachonikolis IG, Mouzas IA (2001) Quality of life of Greek patients with Inflammatory Bowel Disease. Validation of the Greek translation of the Inflammatory Bowel Disease Questionnaire. Digestion 63(4): 240-246.

15. Jowett SL, Seal CJ, Barton JR, Welfare MR (2001) The short inflammatory bowel disease questionnaire is reliable and responsive to clinically important changes in ulcerative colitis. AM J Gastroenterol 96(10): 2921-2928.

16. Drossman DA, Patrick DL, Mitchell CM, Zagami EA, Appelbaum MI (1989) Health-related quality of life in inflammatory bowel disease. Functional status and patient worries and concerns. Dig Dis Sci 34(9): 1379-1386.

17. Hisamatsu $\mathrm{T}$, Inoue $\mathrm{N}$, Yajima $\mathrm{T}$, Izumiya $\mathrm{M}$, Ichikawa $\mathrm{H}$ (2007) Psychological aspects of inflammatory bowel disease. Journal of Gastroenterology 42(suppl 17): 34-40.

18. Camara JA, Ziegler R, Begre S, Schoepfer AM, Kanel R (2009) The role of psychological stress in inflammatory bowel disease: quality assessment of methods of 18 prospective studies and suggestions for future research. Digestion 80(2): 129-139.

19. Mikocka-Walus AA, Turnbull DA, Andrews JM, Moulding NT, Wilson IG, et al. (2008) Psychological problems in gastroenterology outpatients: a 
South Australian experience. Psychological co-morbidity in IBD, IBS and hepatitis C. Clin Pract Epidemiol Ment Health 4: 15.

20. Meder A, Świątkowski M, Meder G, Koza J (2010) Quality of life and coexisting anxiety-depressive disorders in patients with inflammatory bowel disease during relapse and a further 11 months observation. Gastroenterologia Polska 17(4): 273-279.

21. Kurina LM, Goldacre MJ, Yeates D, Gill LE (2001) Depression and anxiety in people with inflammatory bowel disease. J Epidemiol Commun Health 55(10): 716-720

22. Mikocka-Wallus AA (2007) Controversies Surrounding the comorbidity of Depression and Anxiety in IBD patients: A Literature Review. Inflamm Bowel Dis 13(2): 225-234

23. Karwowski C.A, Keljo D, Szigethy E (2009) Strategies to improve quality of life in adolescents with inflammatory bowel disease. Inflamm Bowel Dis 15(11): 1755-1764.

24. Graff LA, Walker JR, Lix L, Clara I, Rawsthorne P, et al. (2006) The relationship of inflammatory bowel disease type and activity to psychological functioning and quality of life. Clin Gastroenterol Hepatol 4(12): 1491-1501.

25. Casellas F, Fontanet G, Borruel N, Malagelada JR (2004) The opinion of patients with inflammatory bowel disease on healthcare received. Rev Esp Enferm Dig 96(3): 174-184.

26. Viazis N, Mantzaris G, Karmiris K, Polymeros D, Kouklakis G, et al. (2012) Inflammatory bowel disease: Greek patients perspective on quality of life, information on the disease, work productivity and family support. Ann Gastroenterol 26(1): 52-58.
Creative Commons Attribution 4.0 International License

For possible submissions Click Here

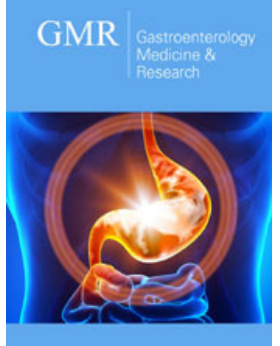

Gastroenterology Medicine \& Research

\section{Benefits of Publishing with us}

- High-level peer review and editorial services

- Freely accessible online immediately upon publication

- Authors retain the copyright to their work

- Licensing it under a Creative Commons license

- Visibility through different online platforms 